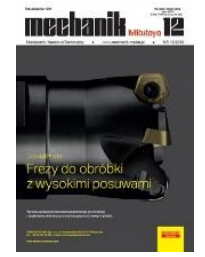

How to cite this article:

Authors: Dariusz Poroś, Stanisław Zaborski, Paweł Karolczak

Title of article: "Heat affected zone analysis of Ti6Al4V after WEDM"

Mechanik, No. 12 (2019)

DOI: https://doi.org/10.17814/mechanik.2019.12.115

\title{
Heat affected zone analysis of Ti6Al4V after WEDM
}

\author{
DARIUSZ POROŚ \\ STANISŁAW ZABORSKI \\ PAWEŁ KAROLCZAK *
}

Dr inż. Dariusz Poroś, dariusz.poros@pwr.edu.pl, https://orcid.org/0000-0002-2336-1859 - Katedra Obrabiarek i Technologii Mechanicznych, Politechnika Wrocławska, Wrocław, Polska

Prof. dr hab. inż. Stanisław Zaborski, stanislaw.zaborski@pwr.edu.pl, https://orcid.org/0000-0001-5232-8800 - Katedra Obrabiarek i Technologii Mechanicznych, Politechnika Wrocławska, Wrocław, Polska

Dr inż. Paweł Karolczak, pawel.karolczak@pwr.edu.pl, https://orcid.org/0000-0002-0595-1580 - Katedra Obrabiarek i Technologii Mechanicznych, Politechnika Wrocławska, Wrocław, Polska

Perspectives of applications WEDM for cutting titanium alloys are presented. There is space to explore how application of proper time parameters and the material of wire electrode for WEDM of titanium alloys affects the surface roughness, structure, the stress and the chemical composition of the formed surface layer.

KEYWORDS: WEDM, titanium alloys, heat affected zone

\section{Introduction}

Machining of titanium alloys with traditional methods presents many disadvantages, both technical and economic, mainly due to low thermal conductivity and the ability to harden as a result of temperature increase. However, due to its strength properties and resistance to corrosive and biologically aggressive environments, titanium is widely used in many industries.

In the pursuit of cost optimization and machining efficiency while maintaining the desired dimensional and shape accuracy of titanium alloy elements, wire electrical discharge machining (WEDM) is increasingly used to shape them. However, it is necessary to select optimal WEDM parameters, mainly time, current and voltage parameters, as well as the type of wire electrode.

\section{Wire electrical discharge machining of titanium and its alloys}

Problem in traditional machining of titanium and its alloys is high temperature during machining, accelerating the tool wear. In addition, there are pseudoplastic behaviors that cause the formation of chips with an unfavorable form. In addition, at higher temperatures, consolidation occurs and chemical reactivity increases. The alternative may be WEDM, which is increasingly used in industry. It allows to process very hard, brittle, composite materials, regardless of their structure and mechanical properties, as well as thin-walled elements.

In [6], it was found that duration of the pulse has the greatest impact on the surface roughness. In turn, to obtain dimensional and shape accuracy, all considered parameters are important, and above all: pulse duration, current and operating voltage. The cutting efficiency depends mainly on the pulse times and the interval between pulses.

It has been shown that in the case of titanium machining, duration of the break does not significantly affect the surface quality and accuracy of the process. This situation allows for using this parameter to stabilize the 
process (deionization of the inter-electrode gap). In analogous tests, the use of high discharge energy speeds up cutting, but long pulse time and high discharge current cause high stress in the surface layer [8].

It is worth mentioning that the state of stress in the surface layer after WEDM can be significantly affected by the materials of the wire electrode. The use of coated electrodes changes the magnitude of these stresses. The authors [1] used three different electrodes: CuZn37 and copper coated with one or two zinc layers. With appropriate values of discharge current and pulse time, it was possible to reduce the magnitude of stress in the surface layer. With WEDM, the electrode with CuZn37 obtained even compressive stresses on the surface.

An effective way to reduce negative impact of surface stresses on the properties of the workpiece is stress relaxation through heat treatment [7]. Research on removing the layer of heat influence in subsequent passes during cutting confirms the possibility of significantly reducing the depth of HAZ (heat affected zone) [2]. The type of dielectric used can also significantly affect the condition of the surface layer [3]. The heat affected zone after WEDM in kerosene reaches deeper below the surface of the material than after machining in distilled water [4].

\section{Research methodology and station for testing the effects of WEDM machining of Ti6Al4V titanium alloy}

The purpose of this study is to analyze the impact of time parameters and electrode material on WEDM effects. BEDRA zinc plated brass electrode with a diameter of $0.25 \mathrm{~mm}$ was selected as a result of comparative tests of brass, copper and zinc coated electrodes [5]. Experimental research included two stages, which are a consequence of the stated objectives:

- defining the function of the test object in the form of a regression function describing the impact of time parameters on cutting surface efficiency and surface roughness after treatment, using the PS/DS-P program: $\lambda$,

- graphical presentation of the obtained dependences on WEDM time parameters.

The effect of these factors on the depth of thermally changed layer was also studied using micro-hardness measurements and microscopic images.

To reduce the number of necessary measurements, it was assumed that surface cutting performance and surface roughness significantly depend on:

- discharge time - ON [ $\mu \mathrm{s}]$,

- pause time between discharges - OFF [ $\mu \mathrm{s}]$.

Cutting tests were carried out on a Sodick AQ 300L wire EDM. The machine structure is largely ceramic. The ceramics used are characterized by at least twice as low coefficient of thermal expansion as traditional materials and high corrosion resistance.

Ceramic body of the $Z$ axis ensures high thermal stability during machining. Stable wire routing allows to reduce the offset, and thus - to obtain the set surface and geometry with fewer passes than in machines with traditional drive. The use of ceramics in many components has extended their service life. The machine's advantage is modern, 64-bit control, based on the Windows NT operating system, with a built-in four-axis CAD/CAM program.

The tests were carried out with CuZn37 brass wire coated with a zinc layer. It should be added that currently, fast threading equipment requires that the wire has a strength of $\sigma_{\mathrm{y}}>750 \mathrm{~N} \cdot \mathrm{mm}^{-2}$ with a diameter of $\varnothing 0.25$ $\mathrm{mm}$, and this condition is not met by any copper wire available on the market. Introduction of brass has allowed an increase in the process efficiency without compromising accuracy, since the strength of brass wire is about three times higher than that of copper. Sporadically, molybdenum electrode material with strength twice as high as brass is used. Its lower resistivity also speaks in favor of this solution. Molybdenum wire is recommended primarily for accurate cutting [5].

During cutting, one-pass was used. Height of the cut elements was $10 \mathrm{~mm}$. The machining time parameters were changed. $R z$ was chosen as a representative roughness parameter for graphical representation of the relationship.

\section{WEDM performance of Ti6Al4V alloy and surface roughness after WEDM}

The surface performance of WEDM was determined as the product of the cutting speed and the height of the cut element. Increased discharge time and/or shortened gap between discharges increases the cutting performance. Regression coefficients were calculated according to the principles of regression analysis in second order rotatable planning. The dependence of performance on time parameters is shown in fig. 1. 


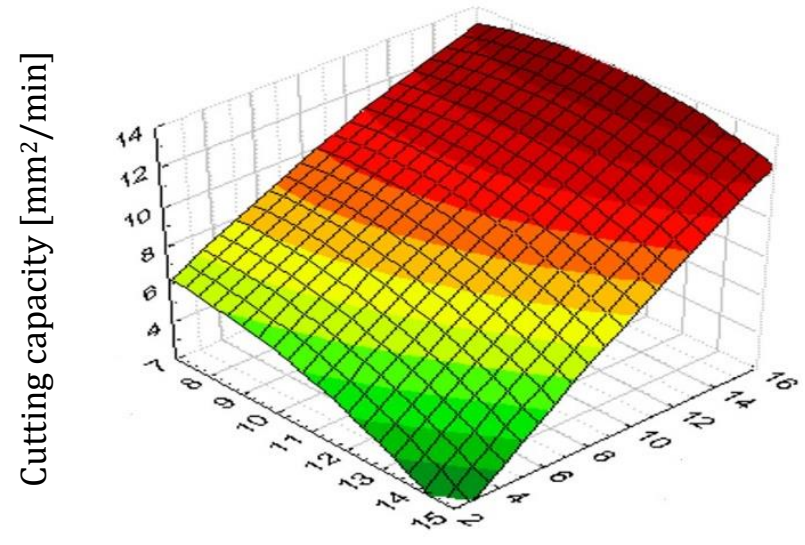

Break time $[\mu \mathrm{s}] \quad$ Discharge time $[\mu \mathrm{s}]$

Fig. 1. Object function for cutting performance of Ti6Al4V alloy from WEDM time parameters

On the profilographometer of the Mitutoyo SV-3200 company, roughness of machined elements in 2D and $3 \mathrm{D}$ as well as material content of the surface were measured. The measurements used a diamond needle with a cone rounding radius of $2 \mu \mathrm{m}$ and angle of $60^{\circ}$. The tip stroke was $800 \mu \mathrm{m}$. The profilographometer was equipped with a 3D measuring table with a resolution of $0.05 \mu \mathrm{m}$. The FORMTRACEPAK measurement software and 3D analysis - MCube Ultimate were applied. Rz was chosen as the roughness parameter of WEDM cut surfaces (fig. 2).

It has been found that extending the discharge time causes an increase in surface roughness after machining. The interval between discharges has less effect on the surface quality, but its elongation results in a lower roughness. The rough surface finish is quite high. The $R z$ parameter reaches up to several micrometers. However, it is worth paying attention to the isotropic structure characteristic of electro-erosion machining visible in the 3D image (fig. 3). It is advantageous and allows to obtain equal bearing load of the material surface regardless of the measuring direction.

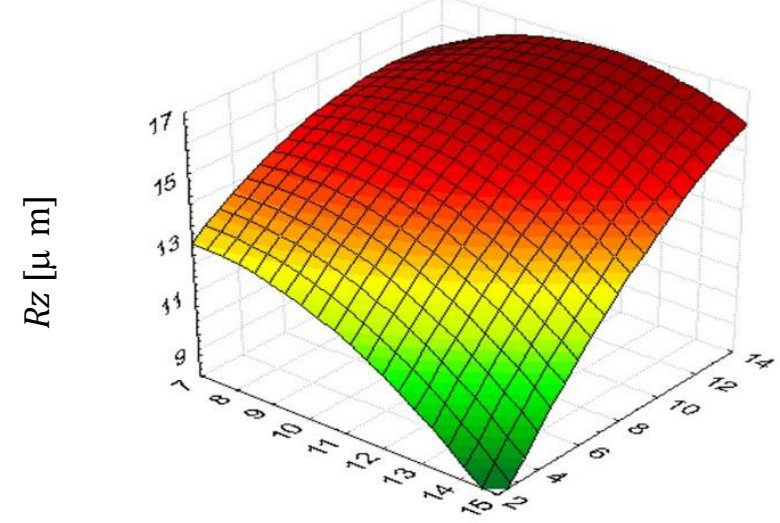

Break time $[\mu \mathrm{s}] \quad$ Discharge time $[\mu \mathrm{s}]$

Fig. 2. Dependence of Ti6Al4V surface roughness on WEDM time parameters

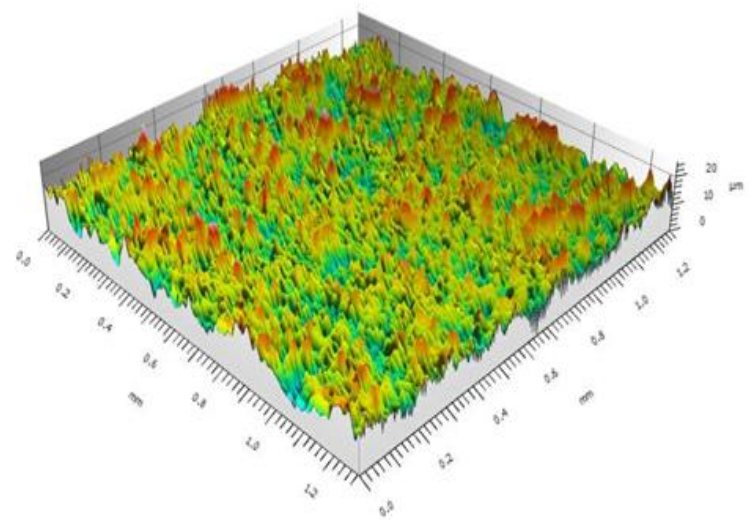

Fig. 3. Image of 3D surface roughness after WEDM 


\section{Heat affected zone}

There are many pores, microcracks and craters of varying depth on the roughly WEDM cut surface. Such imperfections under conditions of increased load can become undesirable stress concentrators. Conditions prevailing during electrical discharge cutting favor the formation of HAZ. The picture of the surface layer after WEDM of the tested titanium alloy is shown in fig. 4. The heat affected zone reaching deep into the material must be minimized, because although it is not a problem in some applications, it is usually characterized by changed structure and properties, e.g. increased hardness. As a more brittle layer, if damaged, it can initiate the deepening of the resulting crack to the core of the material.

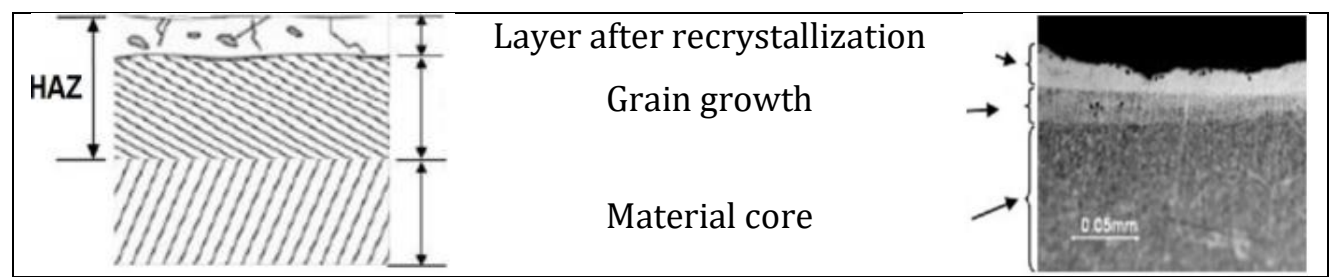

Fig. 4. Ti6Al4V surface layer after electro-erosion treatment. Numerous micro craters visible as a result of electric discharges during WEDM

High temperature and fast surface cooling cause uneven temperature distribution between layers of material. Stresses that can be compressive or tensile remain in the material after machining. Usually, these are tensile stresses, undesirable due to the decrease in mechanical properties of the material.

As a result of the analysis of the depth of thermally changed layer, it was possible to demonstrate the effectiveness of using a coated electrode. The average HAZ depth after cutting with a brass electrode is respectively $80 \div 25 \mu \mathrm{m}$ after rough cutting. The use of zinc coated electrode allowed for limiting the HAZ depth to the range of $50 \div 15 \mu \mathrm{m}$ after rough cutting. The depth of thermally changed zone was confirmed by micro-hardness measurements (fig. 5). Zinc-coated brass electrodes are a combination of zinc with low melting point $\left(420^{\circ} \mathrm{C}\right)$ and high sublimation pressure with copper $\left(1080^{\circ} \mathrm{C}\right)$ in the $\mathrm{CuZn} 37$ alloy. The authors attribute this effect to the action of zinc vapors on limiting the heat flow. During WEDM with a coated electrode (fig. 6), zinc from the outer surface is sublimated, which reduces the amount of particles emitted into the gap.

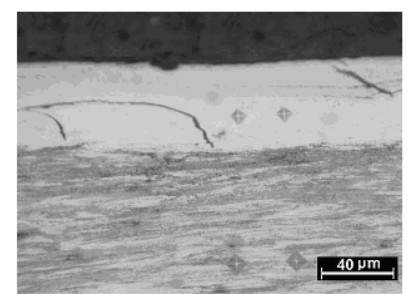

Fig. 5. Cross section after hardness measurement to identify the depth of HAZ

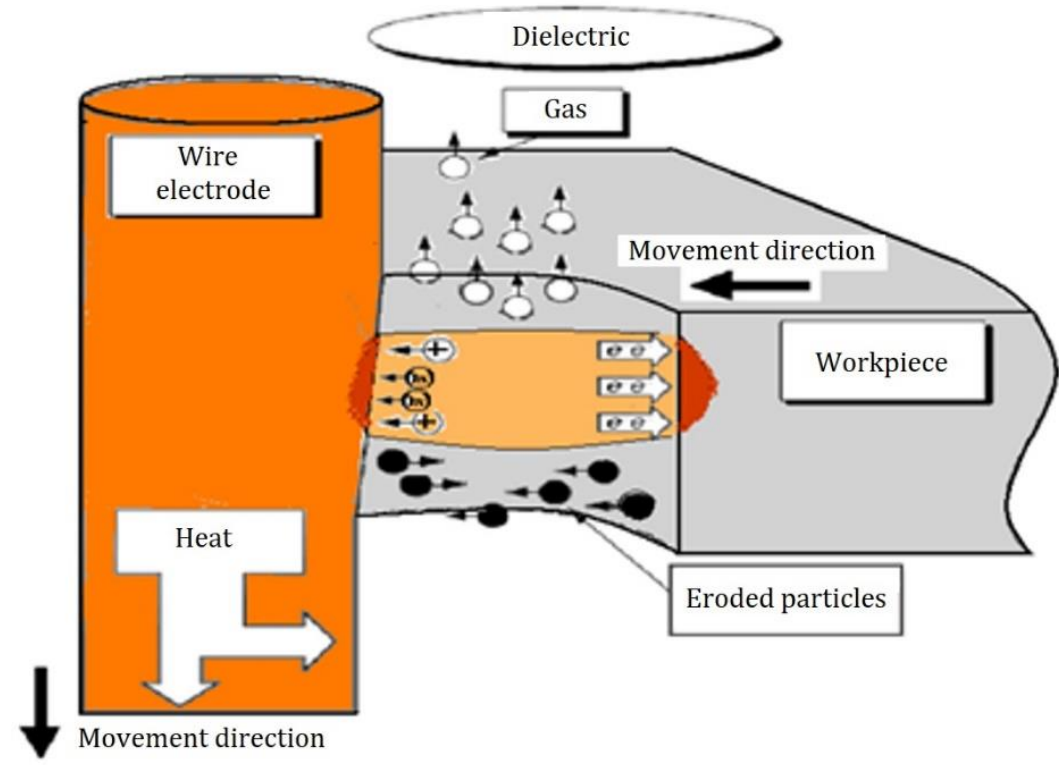

Fig. 6. Picture of the inter-electrode gap taking into account the evaporation of zinc from the surface of the wire electrode

Instead of molten metal particles and evaporating dielectric, the gap is largely filled with zinc vapor. This gas has lower thermal conductivity than e.g. molten copper. This reduces the penetration of heat into the workpiece. The thickness of thermally changed layer varies depending on the energy that is supplied to the electrode gap during cutting. The highest value is obtained after rough cutting. In subsequent passes, the surface roughness peaks are cut off, and much less energy reaches the gap. 


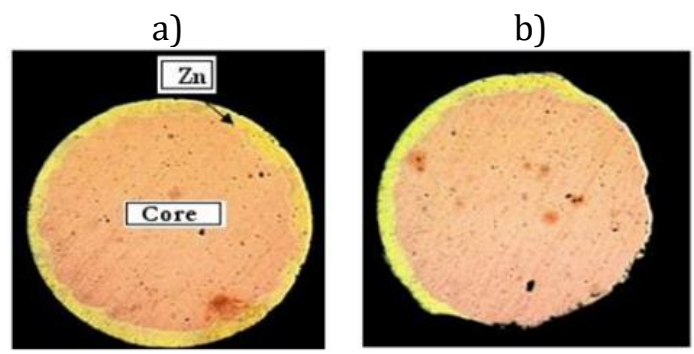

Fig. 7. Cross section of BEDRA zinc plated brass wire electrode: a) new, b) after WEDM

The HAZ thickness measured after subsequent passes decreases. The effect of HAZ reduction using the effect of evaporation and sublimation of zinc is confirmed by photos of the wire cross-section after WEDM (fig. 7). Zinc layer applied to the wire electrode in the production process evaporated from the surface of the brass core. This effect is visible only on the surface directed in the direction of cutting.

\section{Summary and conclusions}

- With increasing electrical discharge time, process efficiency increases. This in turn increases the roughness $R z$ of the machined surface.

- Extending the gap between discharges using both electrodes is an effective way to increase the stability of cutting process without compromising the process efficiency.

- Problems such as thick HAZ, tensile stress and surface microcracks can be reduced and even eliminated by choosing the right machining parameters, number of cutting steps (number of passes) and effective finishing (e.g. burnishing).

- Thickness of the layer thermally changed after WEDM depends, among others, on the duration of the ON discharge and the voltage as well as the operating current. The thickness of the HAZ layer increases with longer discharge times.

- Thermally changed layer visible on the surface has different structure and higher hardness.

- HAZ consists of two areas. The outer is melted workpiece contaminated with wire material. The second, deeper one, is the structure changed mainly by grain growth.

- The sublimable zinc outer wire layer limits the HAZ depth.

- The outer layers of the WEDM cut titanium alloy have increased hardness. Variable hardness within the outer layer can have significant impact on the deterioration of fatigue strength of WEDM cut elements made of Ti6Al4V.

\section{REFERENCES}

[1] Antar M.T., Soo S.L., Aspinwall D.K., Jones D., Perez R. "Productivity and Workpiece Surface Integrity When WEDM Aerospace Alloys Using Coated Wires". Procedia Engineering. 19 (2011): 3-8, https://doi.org/10.1016/j.proeng.2011.11.071.

[2] Aspinwall D.K., Soo S.L., Berrisford A.E., Walder G. "Workpiece surface roughness and integrity after WEDM of Ti-6Al-4V and Inconel 718 using minimum damage generator technology". CIRP Annals - Manufacturing Technology. 57 (2008): 187, https://doi.org/10.1016/j.cirp.2008.03.054.

[3] Chen S.L., Yan B.H., Huang F.Y. "Influence of kerosene and distilled water as dielectrics on the electric discharge machining characteristics of Ti-6A1-4V". Journal of Materials Processing Technology. 87 (1999): 107, https://doi.org/10.1016/S0924-0136(98)00340-9.

[4] Kibria G., Sarkar B.R., Pradhan B.B. "Comparative study of different dielectrics for micro-EDM performance during microhole machining of Ti-6Al-4V alloy”. Int J Adv Manuf Technol. 48 (2010): 557, DOI 10.1007/s00170-0092298-y.

[5] Poroś D., Zaborski S. "Semi-empirical model of efficiency of wire electric discharge machining of hard-to-machine materials". J. Mat. Proc. Technol. 209, 3 (2009): 1247-1253, DOI: 10.1016/j.jmatprotec.2008.03.046.

[6] Sarkar S., Miitra S., Bhattacharyya B. "Parametric analysis and optimization of wire electrical discharge machining of gamma-titanium aluminide alloy". Journal of Materials Processing Technology. 159 (2005): 286-294, https://doi.org/10.1016/j.jmatprotec.2004.10.009.

[7] Strasky P., Janecek J., Harcuba M., Bukovina M., Wagner L. "The effect of microstructure on fatigue performance of Ti-6Al-4V alloy after EDM surface treatment for application in orthopaedics". Journal of the mathematical behaviour of biomedical materials. 4 (2011): 1955, https://doi.org/10.1016/j.jmbbm.2011.06.012.

[8] Yadav V., Jain V.K., Dixit P.M. "Thermal stresses due to electrical discharge machining". International Journal of Machine Tools \& Manufacture. 42 (2002): 877, https://doi.org/10.1016/S0890-6955(02)00029-9. 